\title{
Nicotine Activates Nuclear Factor of Activated T Cells c2 (NFATc2) and Prevents Cell Cycle Entry in T Cells
}

\author{
Ashley A. Frazer-Abel, Shairaz Baksh, ${ }^{1}$ Susan P. Fosmire, Derall Willis, Angela M. Pierce, ${ }^{2}$ \\ Heather Meylemans, Darwin S. Linthicum, Steven J. Burakoff, ${ }^{3}$ Teresa Coons, \\ Donald Bellgrau, and Jaime F. Modiano
}

Integrated Department of Immunology, University of Colorado Health Sciences Center, Denver, Colorado (A.A.F.-A., S.P.F., A.M.P., H.M., D.B., J.F.M.); AMC Cancer Center and Donald Monk Cancer Research Foundation, Denver, Colorado (A.A.F.-A., S.P.F., A.M.P., H.M., J.F.M.); Department of Pediatric Oncology, the Dana-Farber Cancer Institute, Harvard Medical School, Boston, Massachusetts (S.B., S.J.B.); Saccomanno Research Institute, Grand Junction, Colorado (D.W., T.C.); Mannaki Whenua, Landcare Research, Lincoln, New Zealand (D.S.L.); and University of Colorado Cancer Center, Denver, Colorado (D.B., J.F.M.)

Received April 15, 2004; accepted July 1, 2004

\begin{abstract}
We used primary peripheral blood $T$ cells, a population that exists in $\mathrm{G}_{0}$ and can be stimulated to enter the cell cycle synchronously, to define more precisely the effects of nicotine on pathways that control cell cycle entry and progression. Our data show that nicotine decreased the ability of $T$ cells to transit through the $\mathrm{G}_{0} / \mathrm{G}_{1}$ boundary (acquire competence) and respond to progression signals. These effects were due to nuclear factor of activated T cells c2 (NFATc2)-dependent repression of cyclin-dependent kinase 4 (CDK4) expression. Growth arrest at the $G_{0} / G_{1}$ boundary was further enforced by inhibition of cyclin D2 expression and by increased expression and stabilization of p27Kip1. Intriguingly, T cells from habitual users of tobacco products and from NFATc2-
\end{abstract}

deficient mice constitutively expressed CDK4 and were resistant to the antiproliferative effects of nicotine. These results indicate that nicotine impairs T cell cycle entry through NFATc2-dependent mechanisms and suggest that, in the face of chronic nicotine exposure, selection may favor cells that can evade these effects. We postulate that cross talk between nicotinic acetylcholine receptors and growth factor receptor-activated pathways offers a novel mechanism by which nicotine may directly impinge on cell cycle progression. This offers insight into possible reasons that underlie the unique effects of nicotine on distinct cell types and identifies new targets that may be useful control tobacco-related diseases.
Previous studies show that nicotine can act as a mitogen in endothelial and smooth muscle cells (Carty et al., 1997; Villablanca, 1998), but it can inhibit proliferation of lympho-

This study was supported in part by a grant from the Monfort Family Foundation to the University of Colorado Cancer Center and by Grants R55 CA86432 from the National Institutes of Health, RSG-02-173-01-LIB from the American Cancer Society, 0791 from the Smokeless Tobacco Research Council, and by a grant from the Philip Morris External Research Program (to J.F.M.). A.A.F.-A. was supported by a fellowship from the University of Colorado Cancer Center and by Grant NRSA F32 AI50392 from the National Institutes of Health. S.B. was supported by Fellowship 01-047 from the Association for International Cancer Research. H.M. was supported in part by an educational grant (R25 CA49981) from the National Cancer Institute. The University of Colorado Cancer Center Flow Cytometry Core is supported by Grant P30 CA46934 from the National Cancer Institute.

${ }^{1}$ Present address: Department of Medicine, Beth Israel Deaconess Hospital, Harvard Medical School, Boston, MA

2 Present address: Aegis Creative Communications, Littleton, CO.

${ }^{3}$ Present address: Skirball Institute of Biomolecular Medicine, New York University School of Medicine, New York, NY.

Article, publication date, and citation information can be found at http://jpet.aspetjournals.org.

doi:10.1124/jpet.104.070060 cytes and other cells (Theilig et al., 1994; Geng et al., 1995, 1996; Zhang and Petro, 1996; Giannopoulou et al., 2001). To address this paradox, we chose to examine the effects of nicotine on cell cycle entry and progression using a "competence and progression" system of human peripheral blood T lymphocytes (PBTs) (Modiano et al., 1999). We chose this system because, unlike other cultured cells, PBTs comprise a population of normal cells in $\mathrm{G}_{0}$ that can be synchronously stimulated to enter the cell cycle, thus providing a fairly unique opportunity to gain insights into the effects of nicotine not only on $\mathrm{G}_{1}$ phase progression but also on the transition from $G_{0}$ to $G_{1}$.

Nicotine acts by binding homopentameric or heteropentameric nicotinic acetylcholine receptors (nAChRs) that function as ligand-gated calcium channels (Leonard and Bertrand, 2001). Nicotine promotes increased intracellular calcium $\left(\mathrm{Ca}_{\mathrm{i}}{ }^{2+}\right)$ levels in rat lymphocytes (Geng et al., 1995, 1996; Sopori et al., 1998), and although sustained calcium

ABBREVIATIONS: PBT, peripheral blood T cell; $\mathrm{nAChR}$, nicotinic acetylcholine receptor; $\mathrm{Ca}_{\mathrm{i}}{ }^{2+}$, intracellular ionized calcium; $\mathrm{NFAT}$, nuclear factor of activated T cells; IL-2, interleukin-2; AP-1, activator protein-1; CDK, cyclin-dependent kinase; PBS, phosphate-buffered saline; FBS, fetal bovine serum; PHA, phytohemagglutinin; HEX, hexamethonium; DH $\beta$ e, dihydro- $\beta$-erythroidin; $\alpha$-BTX, $\alpha$-bungarotoxin; dTC, D-tubocurarine; PMA, phorbol myristate acetate; CsA, cyclosporin A; BrdU, bromodeoxyuridine; PCR, polymerase chain reaction; GFP, green fluorescent protein. 
mobilization can promote $\mathrm{T}$ cell activation (Modiano et al., 1988), elevations of $\mathrm{Ca}_{\mathrm{i}}{ }^{2+}$ in the absence of costimulation can lead to T cell anergy or unresponsiveness (Macian et al., 2002; Nel and Slaughter, 2002). The mechanisms for this calciumdependent unresponsiveness are incompletely understood, but they may include receptor desensitization, altered or aberrant activation of signaling proteins or transcription factors, resistance to cytokine signals, or combinations thereof. Hence, the inhibitory effects of nicotine on lymphocyte proliferation may be due to inappropriate initiation of activation cascades that ultimately lead to an anergic state (Geng et al., 1996; Kalra et al., 2000).

Recent work shows that calcium-dependent anergy is largely mediated by activation of the nuclear factor of activated T cells c2 (NFATc2, also know as NFAT1 or NFATp) (Macian et al., 2002). NFATc2 was initially characterized as an essential component of the machinery that led to interleukin-2 (IL-2) production and the generation of an immune response in activated T cells (Crabtree and Olson, 2002). However, without activation of activator protein-1 (AP-1) transcription factors, NFATc2 acts as a strong repressor of the $\mathrm{G}_{0} / \mathrm{G}_{1}$ transition kinase CDK4 (Baksh et al., 2002). The importance of CDK4 to regulate cell cycle entry was underscored by the observation that "resting" $\mathrm{T}$ cells from healthy individuals, which constitutively expressed CDK4 and had demonstrable CDK4 activity, could respond to cytokine growth signals in the absence of antigenic stimulation (Modiano et al., 2000). Nevertheless, a mechanistic insight for this phenotype, which comprised about $25 \%$ of the population examined, was not defined. Here, we show that nicotine activates NFATc2 and reduces CDK4 expression leading to cytokine unresponsiveness and cell cycle arrest. Intriguingly, resting $\mathrm{T}$ cells isolated from tobacco users, who constitute approximately $25 \%$ of the adult population, had constitutive CDK4 expression and were insensitive to the inhibitory effects of nicotine, offering one explanation for our previous observation. Our data also suggest that activation of CDK4 and loss of the checkpoint controls for the $G_{0} / G_{1}$ transition may contribute to the pathology of tobacco-related diseases, suggesting that ablating this pathway may a suitable strategy for intervention.

\section{Materials and Methods}

Chemicals and Reagents. Tissue culture materials were obtained from VWR (West Chester, PA), media from Invitrogen (Carlsbad, CA), and chemicals from Sigma-Aldrich (St. Louis, MO) unless otherwise specified. Human anti-CD3 antibody (Orthoclone OKT3; Ortho Diagnostic Systems, Raritan, NJ) and murine anti-CD3 antibody (2C-11; BD Biosciences PharMingen, San Diego, CA) were dissolved in phosphate-buffered saline (PBS) with 5\% fetal bovine serum (FBS; Hyclone Laboratories, Logan, UT). Phytohemagglutinin (PHA; a $\mathrm{T}$ cell mitogen) and $\mathrm{nAChR}$ antagonists hexamethonium (HEX), dihydro- $\beta$-erythroidin ( $\mathrm{DH} \beta \mathrm{e}), \alpha$-bungarotoxin $(\alpha$-BTX), and D-tubocurarine (dTC) were dissolved in sterile water. Nicotine tartarate salt was dissolved in PBS; tacrolimus (FK506, an antagonist of calcineurin and NFAT; Calbiochem, San Diego, CA) was dissolved in $100 \%$ ethanol; phorbol myristate acetate (PMA; a protein kinase C activator that serves as a costimulator for $\mathrm{T}$ cell activation) and cyclosporin A [cyclosporine A ( CsA), an antagonist of calcineurin and NFAT; Calbiochem]were dissolved in dimethyl sulfoxide. All compounds were diluted at least 1000 -fold in cell cultures. Selected experiments from this study, as well as previous experience from our laboratory, indicate that the addition of sterile water, PBS, dimethyl sulfoxide, or ethanol to unstimulated $\mathrm{T}$ cells or to activated $\mathrm{T}$ cells at equivalent concentrations to those used to dilute the chemical compounds does not affect the parameters measured. Human recombinant IL-2 (a cytokine that promotes passage of $\mathrm{T}$ cells through the restriction point of the $G_{1}$ phase) was obtained from Hoffman-La Roche (Nutley, NJ) through the Biologic Response Modifiers Program, Division of Cancer Treatment, National Cancer Institute (Frederick, MD).

Cell Culture. Procedures using human cells and mouse cells were reviewed and approved by appropriate Institutional Review Boards and Institutional Animal Care and Use Committees, respectively. Whole-blood or apheresis residues were obtained from healthy adult volunteers (21 years or older) who provided information on use of tobacco products through questionnaires. The demographics (age, ethnicity, gender) of individuals in the sample that did not use tobacco products were similar to those in the sample that did. Independent verification of tobacco use (plasma or urinary cotinine measurements) could not be performed in the samples because it was not part of the Institutional Review Boards-approved protocols for use of human subjects in this project. All data presented here are from individuals who reported no use of tobacco products, unless otherwise indicated. PBTs were purified from blood products that were incubated with $20 \mu \mathrm{l}$ of RosetteSep Human T Cell Enrichment Cocktail (StemCell Technologies, Vancouver, BC, Canada) per $1 \times 10^{8}$ leukocytes to rosette unwanted cells, followed by Ficoll-Hypaque $(1.077 \mathrm{~g} / \mathrm{ml})$ density gradient centrifugation. This procedure reproducibly generated lymphocyte populations consisting of $>97 \% \mathrm{CD}^{+}$ $\mathrm{T}$ cells with $<1 \%$ accessory cells $\left(\mathrm{CD} 20^{+}\right.$or $\left.\mathrm{CD} 14^{+}\right)$. The generation of NFATc2-deficient mice was reported previously (Xanthoudakis et al., 1996). C57BL/6 mice were purchased from The Jackson Laboratory (Bar Harbor, ME). Murine T cells were enriched from spleens using the EasySep Negative Selection Mouse T Cell Enrichment kit (StemCell Technologies). This procedure similarly yielded $>97 \%$ CD3 $+\mathrm{T}$ cells, with $<1 \% \mathrm{CD} 19+\mathrm{B}$ cells and CD14+ monocytes. PBTs and human Jurkat T cells were cultured in RPMI 1640 containing $2 \mathrm{mM}$ L-glutamine, 10\% FBS, $2 \mathrm{mM}$ sodium pyruvate, and 10 $\mathrm{mM}$ HEPES. Mouse T cells were cultured in the same media with 55 $\mu \mathrm{M}$ 2-mercaptoethanol. DD-1 endothelial cells were grown in F12-K media (American Type Culture Collection, Manassas, VA) supplemented with 10\% FBS (Hyclone Laboratories), $0.1 \mathrm{mg} / \mathrm{ml}$ Heparin (Sigma-Aldrich), and $50 \mu \mathrm{g} / \mathrm{ml}$ Endothelial Cell Growth Supplement (BD Biosciences Discovery Labware, Bedford, MA).

Proliferation Assays. T cells were stimulated to acquire competence (traverse the $\mathrm{G}_{0} / \mathrm{G}_{1}$ transition and respond to IL-2 progression signals) using soluble anti-CD3 $(10 \mathrm{ng} / \mathrm{ml})$ or a submitogenic dose of PHA $(0.5 \mu \mathrm{g} / \mathrm{ml}$ ) for $30 \mathrm{~min}$ followed by rigorous washing (Modiano et al., 1999). To ensure reproducibility of the data, proliferative responses were measured independently in two laboratories (T.C. and J.F.M.) using bromodeoxyuridine (BrdU; Roche Molecular Biochemicals, Branchburg, NJ) or ${ }^{3} \mathrm{H}$-Thymidine incorporation (PerkinElmer Life and Analytical Sciences, Boston, MA), respectively, into DNA 40 to $48 \mathrm{~h}$ after the onset of culture. BrdU incorporation was measured using a colorimetric ELISA following the manufacturer's directions. ${ }^{3} \mathrm{H}$-Thymidine incorporation was measured using liquid scintillation spectroscopy as described (Modiano et al., 1988). To determine whether there were differences between conditions in these assays, we used Student's $t$ test for paired samples with two-tailed distribution, considering $P<0.05$ as statistically significant. This test was done using the raw data for replicates within each experiment and using normalized data for the means across multiple experiments. Cell viability and apoptosis were determined microscopically by trypan blue exclusion, by morphological changes, and by uptake of 7-amino-actinomycin D. Differences between treatments with regards to apoptosis and viability also were determined using Student's $t$ test for paired samples. IL-2 in supernatants was measured using the Human IL-2 DuoSet ELISA kit (R\&D Systems, Minneapolis, MN). 
Calcium Mobilization. Cells were loaded with $2 \mu \mathrm{g} / \mathrm{ml}$ Indo-1acetoxymethylester (a fluorescent calcium chelator; Calbiochem) in the presence of $100 \mathrm{nM}$ probenecid for $30 \mathrm{~min}$ at $37^{\circ} \mathrm{C}$, washed, and resuspended in PBS with $1 \%$ FBS for analysis. Alterations in $\mathrm{Ca}_{\mathrm{i}}{ }^{2+}$ were measured using a MoFlo flow cytometer (DakoCytomation Colorado Inc., Fort Collins, CO) or a Tecan GENios plate fluorimeter (Phenix Research Products, Hayward, CA). Nicotine was added exogenously to prewarmed, equilibrated samples at the indicated time and concentration.

Gene and Protein Expression. RNA was isolated from T cells using RNA Wiz (Ambion, Austin, TX). For Northern blots, $10 \mu \mathrm{g}$ of RNA were separated electrophoretically on $1 \%$ agarose $/ 5 \%$ formaldehyde denaturing gels; for dot blots, 5 to $15 \mu \mathrm{g}$ of RNA were blotted directly onto Nytran membranes using a vacuum manifold. RNase protection assays were done using the RiboQuant kit and hCC-1 human cell cycle regulator multiprobe template set (BD Biosciences PharMingen). Immunoblotting was performed using antibodies against CDK4, CDK6, cyclin D2, and NFATc3 (Santa Cruz Biotechnology, Inc., Santa Cruz, CA), NFATc1, NFATc2, and NFATc4 (Affinity BioReagents, Golden, CO), p27Kip1 (NeoMarkers, Fremont, $\mathrm{CA}$ ), and $\beta$-actin (Sigma-Aldrich). Digital images were quantified using NIH Image Software.

Transfections. Fragments from the CDK4 5'-flanking region were cloned into pGL3-Basic (Promega, Madison WI) upstream of the firefly luciferase gene (Baksh et al., 2002). The pRL-TK Renilla expression vector was used to monitor transfection efficiency. Transient transfections were performed using cationic liposomes (Dosper; Roche) or electroporation with an Amaxa nucleofector (Amaxa Biosystems, Köln, Germany) using Human T cell Nucleofector Kit on setting U-14 or Cell line Nucleofector Kit V on setting S-18 as recommended by the manufacturer. Luciferase assays were performed using the Dual Luciferase kit (Promega). The transfection efficiency using the Amaxa nucleofector was $\sim 75 \%$ for Jurkat cells and $\sim 10 \%$ for DD- 1 cells.

Immunofluorescence. An NFATc2 cDNA containing BamHI and HindIII restriction sites was cloned from normal primary $\mathrm{T}$ cells using reverse transcription-PCR. Primers used were: forward, 5'-CCCAAGCTTGGGATGAACGCCCCCGAG-3'; and reverse, 5'-CAAAACATATTATGACGGGATCCCG-3'. The PCR product was subcloned into an enhanced green fluorescent protein (GFP) expression vector (pEGFP-C1; BD Biosciences Clontech, Palo Alto, CA) and transfected into Jurkat cells or into DD-1 cells using the Amaxa nucleofector, with the Human $\mathrm{T}$ cell Kit at setting U-01 for DD-1 cells and Kit-V with setting S-18 for Jurkat cells. Jurkat cells were cultured in 24-well plates, and DD-1 cells were plated in dual chamber slides (Nalge Nunc International, Naperville, IL) and rested overnight before addition of nicotine. For the DD-1, subcellular localization of the GFP-NFATc2 fusion protein was examined using an Olympus IX71 inverted microscope with an Olympus Microfire S79809 cooled digital camera (Scientific Instrument Company, Aurora, CO). Transmitted light images under phase contrast were captured using a gain of 1.0 and exposures ranging from 12 to $60 \mathrm{~ms}$. Fluorescent images were captured using a gain setting of 4.0 and exposures ranging from 2.6 to $4 \mathrm{~s}$. Brightness and contrast for each image were optimized using Photoshop 7.0 (Adobe Systems, Mountain View, CA). Jurkat cells were cultured in six-well plates overnight before transfer to $35-\mathrm{mm}$ plates with glass coverslip bottoms (MatTek, Ashland, MA), and visualized using confocal microscopy on an Olympus IX81 equipped with a spinning disk and a Hamamatsu ORCA II ER CCD camera (Hamamatsu Corporation, Bridgewater, NJ) captured with Slidebook software (Intelligent Imaging, Dayton, $\mathrm{OH}$ ).

NFAT Activation and DNA Binding. We adapted a multiwell assay to examine the capacity of NFAT to bind the core element of the CDK4 promoter (Renard et al., 2001). Two hundred-base pair oligonucleotides from the CDK4 $5{ }^{\prime}$-flanking region (+45 to -155$)$ containing wild-type or mutant NFATc2 binding sites at position +11 (exon 1) were generated by PCR amplification from the B/FB fragment or the M1 mutant fragment, respectively, as templates (Baksh et al., 2002). The forward primer (5'-CGCCGCTCGAGAATGTCAAGCG-3') was biotinylated at the $5^{\prime}$ end; the reverse primer (GCCCAAGCTTATGTGACCAGCTGCC) was not labeled. Biotinylated oligonucleotides were bound to streptavidin-coated 96-well plates (Roche) for $1 \mathrm{~h}$ at $37^{\circ} \mathrm{C}$ in PBS. After washing, $20 \mu \mathrm{l}$ containing purified hemagglutinin-tagged NFATc2 (Baksh et al., 2002), or $10 \mu \mathrm{l}$ of nuclear extracts were mixed with $30 \mu \mathrm{l}$ of binding buffer [4 $\mathrm{mM}$ HEPES, pH 7.4, $100 \mathrm{mM} \mathrm{KCl,} 8 \%$ glycerol, $5 \mathrm{mM}$ dithiothreitol, $0.2 \%$ bovine serum albumin, and $0.016 \%$ poly d (I-C)] and incubated for $1 \mathrm{~h}$ at $25^{\circ} \mathrm{C}$. Anti-NFAT antibody (Santa Cruz Biotechnology, Inc.) was added at a 1:1000 dilution in PBS with $1 \%$ nonfat dried milk for $1 \mathrm{~h}$ at $25^{\circ} \mathrm{C}$ followed by a secondary antibody conjugated to horseradish peroxidase. The color reaction was visualized using a Substrate Reagent Pack (R\&D Systems). Absorbance was measured at $450 \mathrm{~nm}$ with correction at $540 \mathrm{~nm}$. Absorbance of sham-treated wells containing oligonucleotide, but not protein or nuclear extract, was considered background. Electrophoretic mobility shift assays were preformed as described (Baksh et al., 2002).

\section{Results}

Nicotine Inhibits Cell Cycle Entry and Cytokine Responsiveness. To examine the effect of nicotine on cell cycle entry, we used human PBTs stimulated for competence and progression. Normal PBT did not proliferate spontaneously and were refractory to stimulation by IL-2 (Fig. 1A). Induction of competence using soluble anti-CD3 $(10 \mathrm{ng} / \mathrm{ml})$ did not induce proliferation of PBT but enabled the cells to respond to exogenous IL-2 (Fig. 1A). Similar data were found when competence was induced with a submitogenic dose of PHA (Modiano et al., 1999; Modiano et al., 2000). Incubation of PBT with nicotine alone did not promote proliferation or competence. However, the addition of nicotine for $30 \mathrm{~min}$ prior to competence induction inhibited the capacity of PBT to respond to IL-2. Figure 1A shows the inhibitory effect of nicotine in one highly susceptible donor. At the nicotine dose shown $(10 \mu \mathrm{M}$, which is comparable with steady-state concentrations in the blood of habitual smokers, users of smokeless tobacco products, or individuals that use transdermal NIC patches), IL-2-driven proliferation in T cells from 14 nonsmokers was inhibited 19 to $95 \%$, with a mean \pm S.E.M. $=45 \pm 26 \%$. When tested across a range of concentrations ( 1 $\mathrm{nM}-100 \mu \mathrm{M})$ in four donors, the inhibition was dose-dependent. Figure 1B shows the inhibitory effect on IL-2-driven proliferation was evident at a nicotine concentration of $1 \mu \mathrm{M}$. In this group of donors, $10 \mu \mathrm{M}$ nicotine inhibited the proliferative response by $32 \pm 8 \%$, and the inhibition was virtually complete $(95 \pm 6 \%)$ at a nicotine concentration of $50 \mu \mathrm{M}$ (which is less than the peak nicotine concentration found in the blood immediately after smoking a cigarette). The effect did not require the presence of nicotine throughout the culture period, and it was specific because nicotine did not inhibit IL-2 receptor expression in these cells (data not shown). In addition, the effect was not due to cytotoxicity because no significant differences were seen in viability of unstimulated $\mathrm{T}$ cells incubated without $($ mean $=88 \%)$ or with nicotine (mean $=90 \%)$ for up to 4 days based on trypan blue exclusion. Similarly, viability of T cells stimulated with anti-CD3 for up to $36 \mathrm{~h}$ was not significantly different in the presence or absence of nicotine $(<1 \%$ of cells were dead in both cases) as determined by exclusion of 7 -amino-actinomycin D using flow cytometry. 

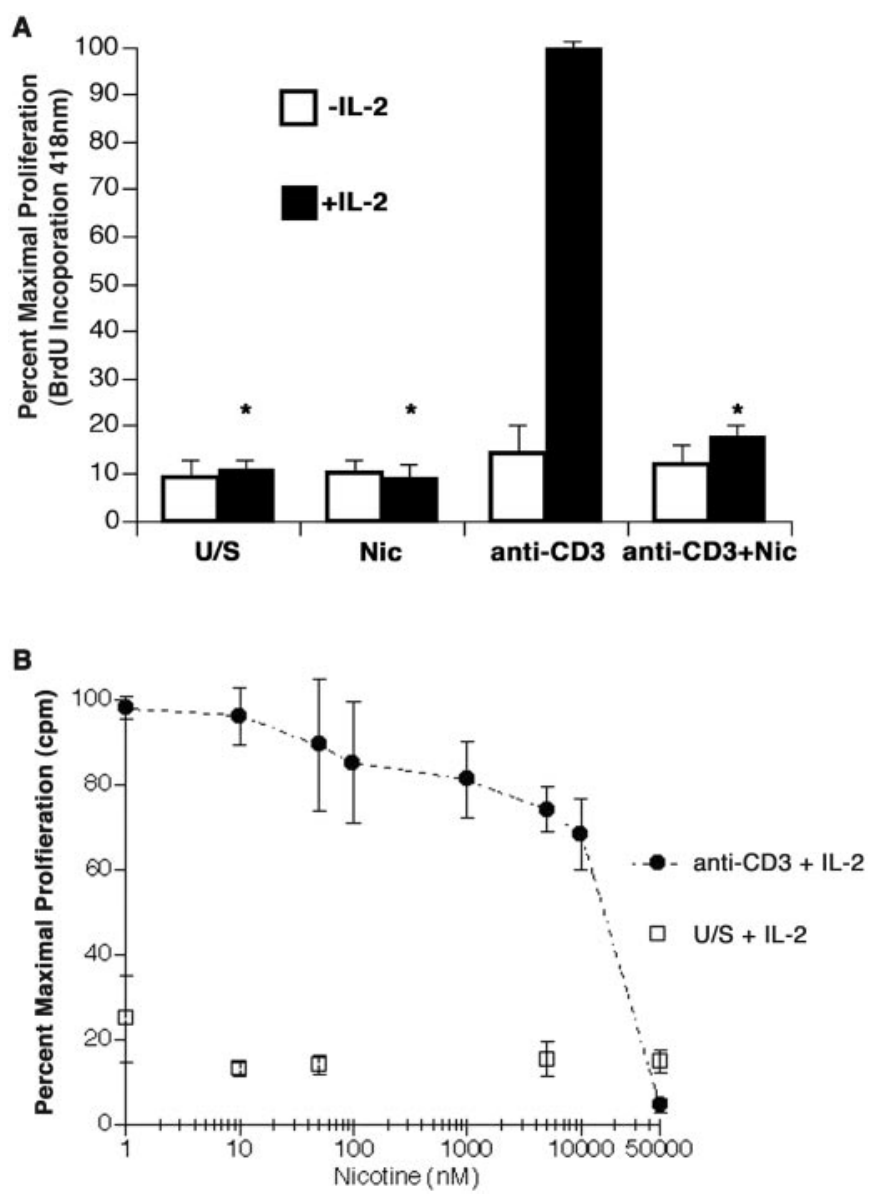

Fig. 1. Nicotine inhibits cytokine responsiveness in human T cells. PBT purified from volunteers who did not report use of tobacco products remained unstimulated (U/S) or were stimulated by anti-CD3 $(10 \mu \mathrm{g} / \mathrm{ml})$ in the presence or absence of nicotine (NIC, $10 \mu \mathrm{M})$, added 30 min prior to stimulation. Proliferation was measured by BrdU uptake $48 \mathrm{~h}$ after stimulation. Data show a representative experiment of 14 independent donors (see Fig. 7). The asterisks indicate values that are significantly different $(P<0.01)$ from those seen in competent T cells treated with IL-2 (maximal stimulation). $P$ values and statistical significance were determined using Student's $t$ test for paired samples with two-tailed distribution.

Nicotine Inhibits Antigen Receptor-Dependent Calcium Mobilization in Human Lymphocytes. The calcium mobilization that follows ligation of $\mathrm{nAChR}$ presented a possible initial mechanism for the nicotine-induced effects on cell cycle progression. The expression of $\mathrm{nAChR}$ that bind $\alpha$-bungarotoxin ( $\alpha 7$ ), as well as of $\alpha 4 \beta 2$-subunit-, $\alpha 3 \beta 4$-subunit-, and $\alpha 5$-subunit-containing $\mathrm{nAChR}$ receptors has been documented in peripheral and splenic lymphocytes in mice (Toyabe et al., 1997; Kuo et al., 2002), and in human peripheral blood lymphocytes (Benhammou et al., 2000). Nicotine promotes calcium mobilization in rat lymphocytes. However, it also is clear chronic exposure to nicotine in vivo can inhibit $\mathrm{T}$ cell receptor-mediated calcium mobilization, possibly through indirect effects mediated by the pituitary-adrenal axis (Sopori, 2002). We evaluated changes in the concentration of $\mathrm{Ca}_{\mathrm{i}}{ }^{2+}$ in human $\mathrm{T}$ lymphocytes treated with nicotine $(0-50 \mu \mathrm{M})$ and soluble anti-CD3 $(10 \mathrm{ng} / \mathrm{ml})$. Stimulation with anti-CD3 showed a characteristic rapid $\mathrm{Ca}_{\mathrm{i}}{ }^{2+}$ rise within $\sim 1$ min of addition followed by a slowly decreasing plateau (Fig. 2A). Pretreatment of T cells with nicotine caused predictable but very modest dose-dependent alterations in $\mathrm{Ca}_{\mathrm{i}}{ }^{2+}$. A small calcium spike was seen within $\sim 1$ min of nicotine addition, but only at doses $>5 \mathrm{nM}$ (Fig. 2A). There also was a small, albeit reproducible, protracted response that was most noticeable at concentrations $<0.5 \mu \mathrm{M}$ and that lasted until the addition of anti-CD3 (Fig. 2A). Two representative concentrations ( $5 \mathrm{nM}$ and $50 \mu \mathrm{M}$ ) required to saturate high- and low-affinity receptors, respectively (Leonard and Bertrand, 2001), are shown in the main panels of Fig. 2, with the full dose response included in the insets. Although the calcium mobilization in response to nicotine alone was modest, a more dramatic nicotine effect was the dose-dependent reduction in calcium mobilization induced by anti-CD3 (Fig. 2A). The inhibition was due to a decrease in the frequency of responding cells only at the highest dose tested $(50 \mu \mathrm{M})$, indicating that, at concentrations between $50 \mathrm{nM}$ and $10 \mu \mathrm{M}$, nicotine blunted anti-CD3-dependent calcium mobilization in virtually all the responding cells. The observation that dTC or HEX reversed this nicotine effect suggests that it was mediated through $\mathrm{nAChR}$ (data not shown).

Nicotine Represses CDK4 Expression. Cell cycle entry and $\mathrm{T}$ cell competence can be defined by expression and activation of the cell cycle kinase CDK4, and calcium-dependent signals are required for both induction and repression of CDK4 expression and activity (Modiano et al., 1999, 2000; Baksh et al., 2002). Therefore, we utilized T cells from people who reported no use of tobacco products to examine the effects of nicotine on expression of CDK4, cyclin D2, and p27Kip1, three proteins that control CDK4 kinase activity during the $\mathrm{G}_{0} / \mathrm{G}_{1}$ transition (Sherr and Roberts, 1995). As reported previously (Modiano et al., 1999, 2000), immunoblotting of unstimulated PBT showed no to minimal levels of CDK4 or cyclin D2, with detectable levels of CDK6 and p27Kip1. The levels of CDK4, CDK6, and cyclin D2, but not p27Kip1 increased upon induction of competence (Fig. 3, A-D) or upon maximal stimulation. The increased levels of CDK4 seen upon induction of competence were inhibited when cells were preincubated with nicotine for $30 \mathrm{~min}$, (Fig. $3 \mathrm{~A})$. The inhibition was specific because nicotine did not affect accumulation of CDK6 in competent T cells (Fig. 3B). Nicotine also inhibited accumulation of cyclin D2 in competent T cells (Fig. 3C), and it increased that of p27Kip1 (Fig. 3D), offering a mechanistic explanation for its effect to promote growth arrest of PBT at the $G_{0} / G_{1}$ transition; that is, nicotine inhibits accumulation of pro-proliferative factors CDK4 and cyclin D2 and increases the levels of antiproliferative p27Kip1. To confirm that the inhibitory effects of nicotine on CDK4 accumulation were mediated by $\mathrm{nAChR}$, we examined the effect of four distinct $\mathrm{nAChR}$ antagonists, $\alpha$-BTX, DH $\beta$ e, HEX, and dTC. Each of these compounds reversed the nicotine-dependent inhibition of CDK4 expression in competent T cells (Fig. 3E). The observation that both low- and high-affinity nAChR antagonists effectively block the nicotine-dependent reduction of CDK4 expression suggests that multiple receptors subunits may be required for this effect.

The Nicotine-Dependent Inhibition of CDK4 Expression Occurs at the mRNA Level. We next examined if the effect of nicotine on CDK4 expression occurred at the transcriptional level. CDK4 message was undetectable in unstimulated $\mathrm{T}$ cells and increased within 3 to $4 \mathrm{~h}$ of competence induction by anti-CD3 (Fig. 4A; Table 1). Nicotine reproducibly inhibited this CDK4 gene expression by as 

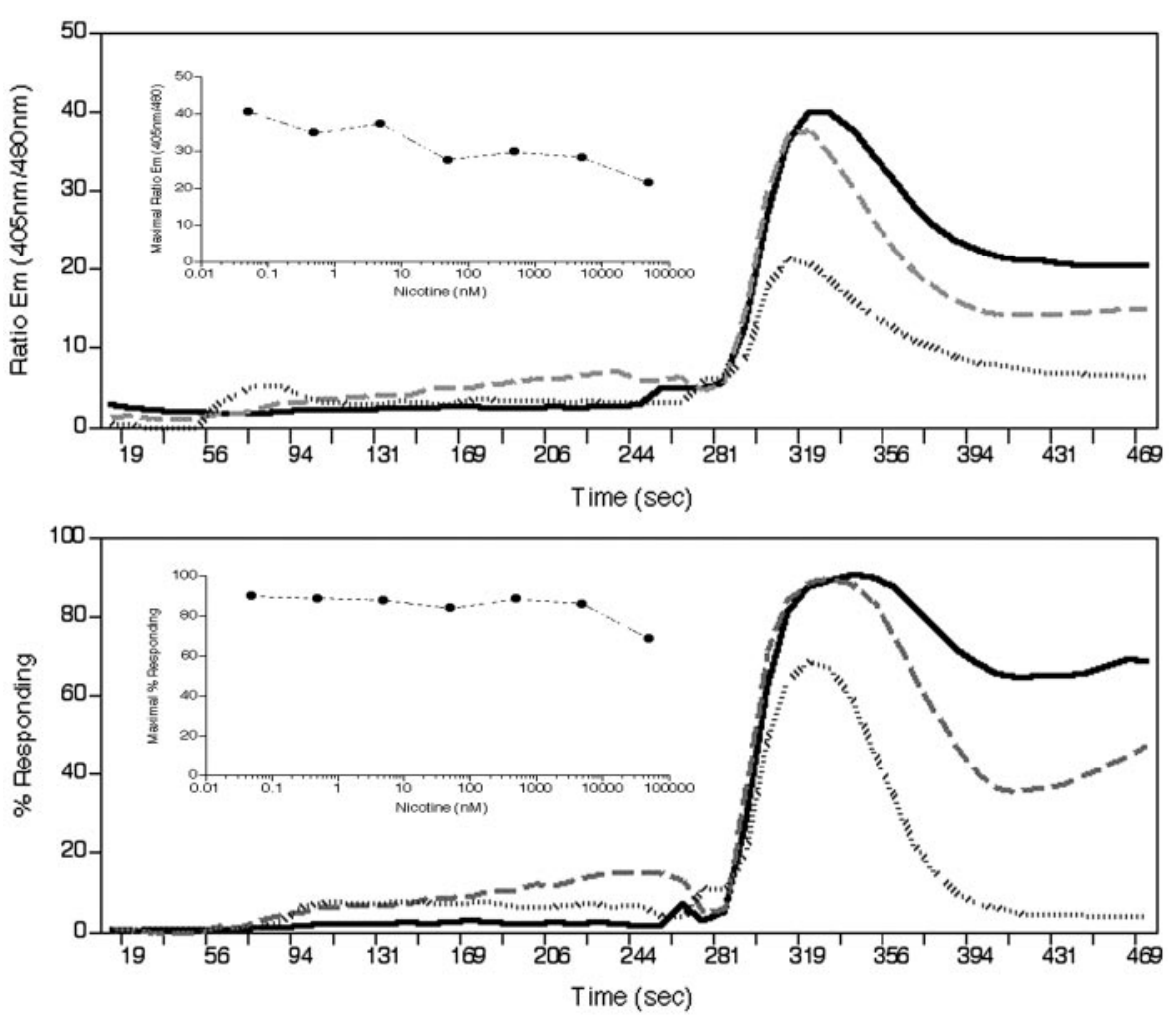

Fig. 2. Calcium mobilization in nicotine-treated human T cells. Cells were treated with nicotine at the indicated concentrations for 5 min prior to the addition of anti-CD3 (10 $\mathrm{ng} / \mathrm{ml})$. Alterations in $\mathrm{Ca}_{\mathrm{i}}{ }^{2+}$ were measured using a MoFlo flow cytometer. A, representative curves for cells treated without $(0 \mathrm{nM})$ or with $(5 \mathrm{nM}$ and $50 \mu \mathrm{M})$ nicotine are shown as the ratio of emission at 405 versus 480 $\mathrm{nm}$ (Indo-1 bound to $\mathrm{Ca}^{2+}$ versus free Indo-1), which is a surrogate measure of mobilized calcium. Inset graph, dose-dependent effect of nicotine to blunt the increase in $\mathrm{Ca}_{\mathrm{i}}{ }^{2+}$ induced by anti-CD3. $\mathrm{B}$, data show the percentage of cells that exhibit a change in the emission ratio, i.e., the percentage of cells responding. Inset graph, fraction of cells that respond to anti-CD3 stimulation as a function of nicotine concentration. much as $75 \%$ (Fig. 4A; Table 1). We surmised that a calciumdependent repressor such as NFATc2 might contribute to the nicotine-dependent inhibition of CDK4 expression (Baksh et al., 2002), a hypothesis supported by the observation that FK506, an inhibitor of the calcineurin/NFAT pathway, partially restored CDK4 expression in nicotine-treated cells (Fig. 4A). To further confirm that the nicotine-dependent inhibition of CDK4 transcription was mediated by NFAT, we used a heterologous reporter construct consisting of 474 bases of genomic CDK45'-flanking sequence (Baksh et al., 2002) (Fig. 4 , B-D). The construct showed constitutive activity in Jurkat cells, which increased 2 - to 3 -fold upon stimulation by soluble anti-CD3 (Fig. 4B). This induction was inhibited by nicotine and restored by FK506 or CsA; it was dose-dependent (Fig. 4C) and required as little as 5 min of exposure prior to stimulation (Fig. 4D).

Nicotine Exposure Activates NFATc2. We next examined if nicotine could directly activate NFATc2 in T cells. Exposure of T lymphocytes to nicotine led to NFATc2 dephosphorylation (a measure of calcineurin-dependent activation; Fig. 5A). NFATc1 and NFATc3 were also detectable in T cells; however, nicotine treatment did not promote dephosphorylation of these proteins as determined by their electrophoretic mobility on one-dimensional immunoblots (NFATc1, Fig. 5B; NFATc3, data not shown). To confirm that the dephosphorylation of NFATc2 was biologically significant, we examined the effects of nicotine on the equilibrium of NFATc2 subcellular distribution using fluorescence confocal microscopy. Jurkat T cells and DD-1 endothelial cells were transfected with a GFP-NFATc2 fusion protein and cultured in the presence or absence of competence-inducing stimuli (anti-CD3 and serum, respectively) with or without nicotine for $4 \mathrm{~h}$. The GFP-NFATc2 construct was confined to the cytoplasmic compartment in unstimulated Jurkat cells, and this steady state was only minimally altered by anti-CD3 alone (Fig. 5C). Under both of these conditions, less than $20 \%$ of the cells showed green fluorescence in the nucleus, indicative of GFP-NFATc2 translocation. Exposure to nicotine prior to stimulation with anti-CD3 produced a shift in the steady state of GFP-NFATc2 localization, leading to detectable fluorescence in the nuclear compartment of $89 \%$ of the cells within $3 \mathrm{~h}$ (Fig. 5C). The nuclear translocation of GFPNFATc2 seen in nicotine-treated cells was blocked by FK506 (Fig. 5C), with only $33 \%$ of the cells showing green fluorescence in the nucleus.

The effect of nicotine to shift the steady state of NFAT localization and promote nuclear translocation was not restricted to T cells. Figure 5D shows that GFP-NFATc2 was present in approximate equilibrium between the nucleus and cytoplasm in untreated DD-1 endothelial cells, but nicotine shifted this steady state and led to preferential localization of the protein to the nuclear compartment. The effects of nicotine in DD-1 cells were not restricted to the transfected GFP-NFATc2. Nicotine treatment of untransfected cells led to decreased vascular endothelial growth factor expression and prevented aggregation of the cells into vessel-like structures, and both of these events were sensitive to FK506 (Fosmire et al., 2004), suggesting they were mediated by activation of endogenous NFAT proteins.

NFATc2 Is Necessary for CDK4 Repression by Nicotine. To confirm that nicotine induced nuclear translocation of active NFAT, we utilized an antibody-based binding assay to measure the ability of nuclear NFAT to bind DNA. We designed oligonucleotides that encompassed positions +45 to 

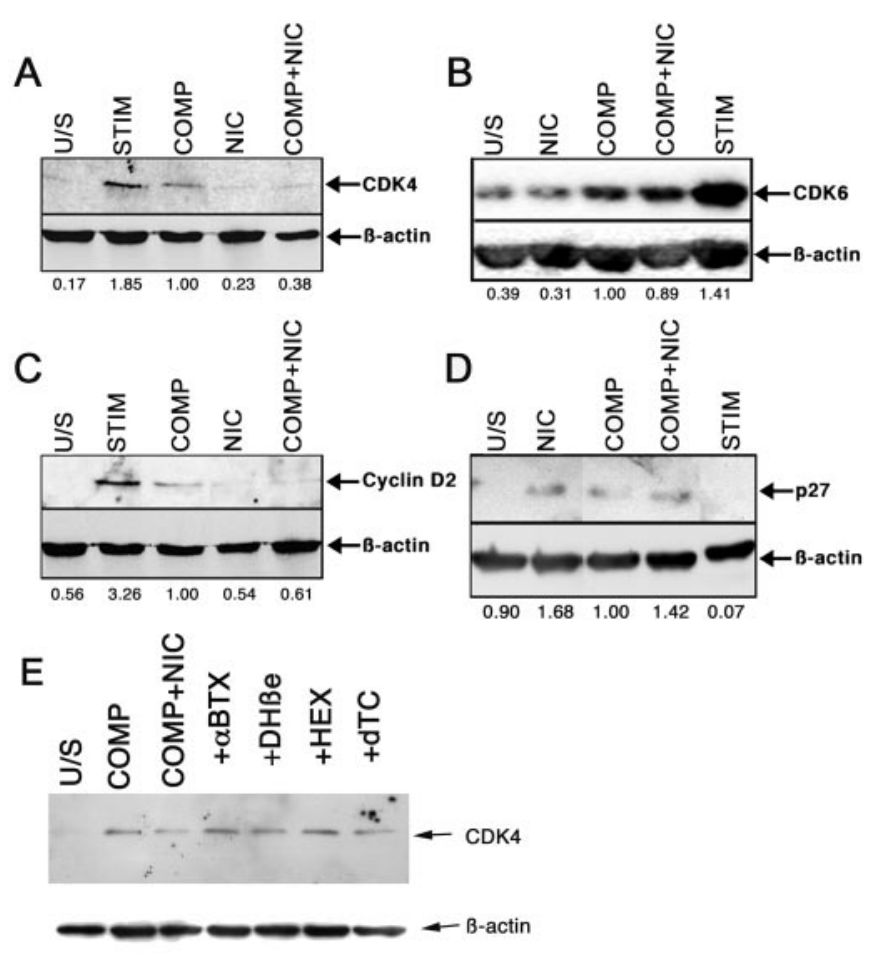

$\begin{array}{lllllll}0.59 & 1.00 & 0.63 & 1.92 & 1.43 & 1.34 & 1.53\end{array}$

Fig. 3. Nicotine inhibits expression of CDK4 and cyclin D2 but increases expression of p27Kip1. PBTs were left untreated or rendered competent with submitogenic concentrations of PHA (COMP) or anti-CD3 in the presence or absence of nicotine (NIC; $10 \mu \mathrm{M})$ as indicated. Alternatively, cells were maximally activated (STIM) using anti-CD3 with PMA as a costimulator. Expression of CDK4 (A), CDK6 (B), cyclin D2 (C), and p27Kip1 (D) was evaluated by immunoblotting. E, PBTs were treated as above, except that cells were preincubated with $\mathrm{nAChR}$ antagonists $\alpha$-BTX $(0.5 \mu \mathrm{M}), \mathrm{DH} \beta 3(50 \mu \mathrm{M}), \operatorname{HEX}(500 \mu \mathrm{M})$, or dTC $(50 \mu \mathrm{M})$ as indicated. For each immunoblot, protein expression was quantified densitometrically using NIH Image, standardized to the levels of $\beta$-actin, and expressed as a fraction of the intensity of the COMP band (which was set to 1.00$)$.

-155 of the CDK4 5'-flanking region, including the NFAT core element at position +11 (Baksh et al., 2002). This element was used in a similar manner to a primary antibody in an ELISA, where it was bound to the bottom of streptavidincoated plates and allowed to interact with NFAT proteins that were present in the nuclear extracts. NFAT was then specifically identified using horseradish peroxidase-labeled antibodies in the colorimetric reaction. NFAT binding activity in Jurkat cells stimulated with soluble anti-CD3 to mimic competence was not significantly different from that seen in unstimulated cells (Fig. 6A). A small increase in NFAT binding was seen in Jurkat cells treated with nicotine alone, which was enhanced substantially in cells that were treated with nicotine and then stimulated with anti-CD3. This latter increase was comparable with that seen in cells maximally stimulated using PMA + ionomycin or PHA, and it was inhibited by pretreatment with either FK506 or CsA (Fig. $6 A)$. Similar results were obtained when NFAT activation was examined using electrophoretic mobility shift assays (not shown). To determine whether the effect of NFAT to inhibit CDK4 transcription required the core element at position +11 of the CDK4 promoter, we used a CDK4-luciferase construct with a mutation at this site that abolished NFAT repression (Baksh et al., 2002). Figure 6B shows that nicotine inhibited the induction of reporter activity in cells ex- pressing the wild-type construct, but not in cells expressing the mutant construct. The importance of this NFAT-dependent inhibition of CDK4 expression was underscored by the observation that cytokine responsiveness in PBT stimulated in the presence of nicotine was restored by FK506 and CsA (Fig. 6C). Finally, if NFATc2 were mechanistically linked to the inhibition of CDK4 expression in nicotine-treated T cells, the expectation would be that cells from NFATc2-deficient mice would be refractory to this effect. Figure $6 \mathrm{D}$ shows that, as was seen in human cells, CDK4 was undetectable in splenic $\mathrm{T}$ cells from wild-type mice, it was induced following competence induction by anti-CD3, and it was reduced by $\sim 30 \%$ in nicotine-treated cells. In contrast, $\mathrm{T}$ cells from NFATc2-deficient mice expressed elevated high levels of CDK4 in the absence of stimulation (Baksh et al., 2002). As we showed before for human $\mathrm{T}$ cells that show spontaneous CDK4 expression, this was slightly reduced upon stimulation by anti-CD3 (Modiano et al., 2000), but it was essentially unaffected (or slightly increased) by nicotine, indicating that the inhibitory effects on CDK4 expression are largely due to activation of NFATc2 by this tobacco-derived alkaloid.

Habitual Use of Tobacco Products Results in an "Activated" T Lymphocyte Phenotype That Is Refractory to Nicotine. We had shown previously that resting T lymphocytes from approximately $25 \%$ of healthy individuals constitutively express CDK4, have demonstrable CDK4 activity, and can respond to cytokine growth signals in the absence of antigenic stimulation (Modiano et al., 2000). However, the reasons for this possible difference in apparently healthy individuals were unclear. We hypothesized that cells chronically exposed to nicotine might evade its antiproliferative effects, providing an impetus for abnormal growth and transformation. To test this hypothesis, we examined proliferation, cytokine responsiveness, and CDK4 expression in 14 and 8 individuals, respectively, who had no history of tobacco use or who were habitual users of tobacco products (smoked $6-20$ cigarettes per day, $n=7$; or used up to 1.5 cans of smokeless tobacco per month, $n=1$ ). Unlike T cells isolated from people with no history of tobacco use, those from tobacco users showed a level of background proliferation (i.e., there was measurable incorporation of ${ }^{3} \mathrm{H}$-thymidine in unstimulated cells). Moreover, PBT from tobacco users were refractory to antiproliferative effects of nicotine showing no statistically significant difference between those conditions tested in the presence or absence of nicotine, with or without IL-2 (Fig. 7, A versus B). In each tobacco user examined, unstimulated PBT showed this distinct, quasi-competent phenotype with constitutive CDK4 mRNA and protein expression and resistance to inhibition by nicotine (Table 1; Figs. 7 and 8).

\section{Discussion}

Experiments to assess the effects of nicotine on cell growth have yielded contradictory results. Nicotine is mitogenic for endothelial and smooth muscle cells (Carty et al., 1997; Villablanca, 1998; Cucina et al., 2000). In contrast, it inhibits proliferation of lymphocytes, airway and oral epithelial cells, and fibroblasts, possibly through direct and indirect mechanisms (Theilig et al., 1994; Geng et al., 1995, 1996; Zhang and Petro, 1996; Giannopoulou et al., 2001; Sopori, 2002). Here, we used a "competence and progression" system that allows examination of the earliest steps of cell cycle entry in a 


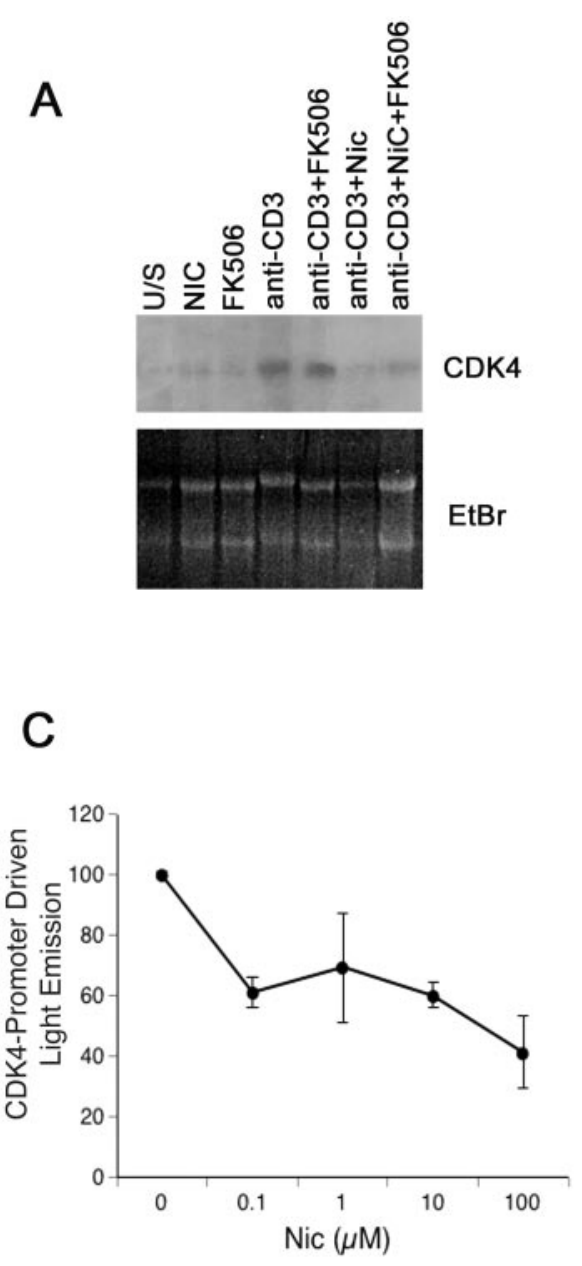

TABLE 1

Effect of nicotine on CDK4 gene expression by competent human PBTs from individuals without history of tobacco use and from habitual users of tobacco products

PBTs were isolated from seven independent donors with no history of tobacco use and from three habitual users of tobacco products and cultured as indicated for 4 to $6 \mathrm{~h}$.

\begin{tabular}{lcc}
\hline \multirow{2}{*}{ Condition } & \multicolumn{2}{c}{ CDK4 mRNA Levels ${ }^{a}$} \\
\cline { 2 - 3 } & Nonsmokers & Smokers \\
\hline Unstimulated & $10.3 \pm 10.0^{b}$ & $54 \pm 20$ \\
Anti-CD3 & 100 & 100 \\
Anti-CD3 + nicotine $(10 \mu \mathrm{M})$ & $53.57 \pm 18.9^{c}$ & $100 \pm 18$ \\
\hline
\end{tabular}

${ }^{a}$ CDK4 mRNA levels were measured by dot blot analysis using $\beta$-actin mRNA as a loading control and normalized to levels seen in cells stimulated with anti-CD3. Data are expressed as means (percentage of anti-CD3) \pm S.E.M. Statistical comparisons between control and experimental conditions were done using Student's $t$ test for paired samples with two-tailed distribution.

${ }^{b}$ One donor exhibited constitutive expression of CDK4 mRNA that was indistinguishable from that seen in the stimulated cells (see Modiano et al., 2000). The mean \pm S.E.M. excluding that donor was $0.22 \pm 0.22$. Significantly different from control (anti-CD3), $P=0.001$.

${ }^{c}$ Significantly different from control (anti-CD3), $P=0.004$.

synchronous, normal cell population. Our results show that nicotine blocks the ability of $\mathrm{T}$ cells (from donors with no history of tobacco use) to cross the $G_{0} / G_{1}$ boundary and acquire competence to respond to progression signals.

Nicotine induced a small, dose-dependent increase in $\mathrm{Ca}_{\mathrm{i}}{ }^{2+}$, but more significantly, it reduced calcium mobilization in response to anti-CD3. The relationship between these two events will require further study. Activation of NFAT transcription factors and repression of CDK4 expression occurred
Fig. 4. Nicotine inhibits CDK4 gene expression. A, CDK4 gene expression was examined by Northern blot analysis in cells stimulated for $6 \mathrm{~h}$ with soluble anti-CD3 in the absence or presence of nicotine (NIC; $10 \mu \mathrm{M})$ or FK506 (100 $\mathrm{nM})$ as indicated. EtBr staining of $18 \mathrm{~S}$ and $28 \mathrm{~S}$ RNA is shown as a loading control. B to D, The activity of a CDK4 heterologous reporter construct (B/FBLuc) containing an NFAT-responsive element at position +11 was examined by transient transfections into Jurkat cells. Values were normalized to the activity of Renilla luciferase. B, cells were treated with $10 \mu \mathrm{M}$ nicotine for $30 \mathrm{~min}$ prior to stimulation using anti-CD3 or preincubated with FK506 or CsA 20 min prior to addition of nicotine. Luciferase activity was examined $4 \mathrm{~h}$ after stimulation. Data show mean change in stimulation ( \pm S.E.M.M.) after $6 \mathrm{~h}$ of culture, where activity of competent cells was $100 \%$. $\mathrm{C}$, cells were treated as in B with the indicated nicotine concentration. The data represent means \pm S.D. of luciferase activity from two independent experiments. D, cells were treated with nicotine (NIC; $10 \mu \mathrm{M}$ ) at the indicated time prior to addition of soluble anti-CD3. Luciferase activity was examined $4 \mathrm{~h}$ after stimulation. Data represent the effect of nicotine on luminescent emission by the heterologous reporter as a function of time. 
A

Primary T Cells
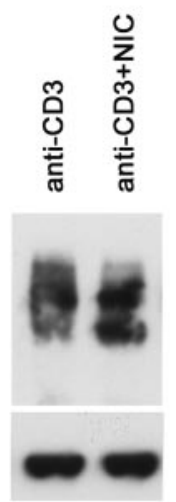

NFATc2p NFATc2

Zap-70

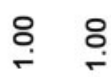

$\stackrel{\circ}{\circ} \stackrel{\circ}{-}$
Jurkat T Cells
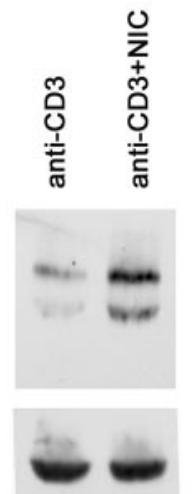

Zap-70

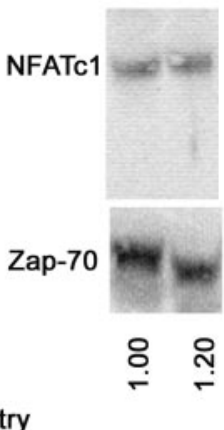

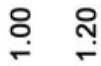

Densitometry

Primary T Cells

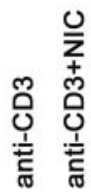

○ ल
C

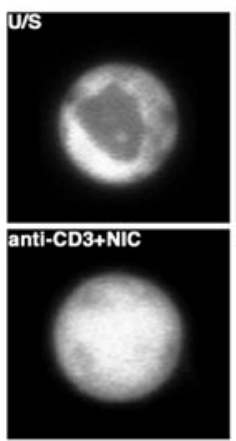

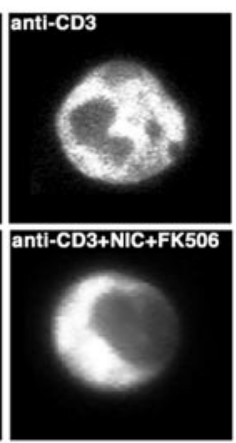

\section{D}

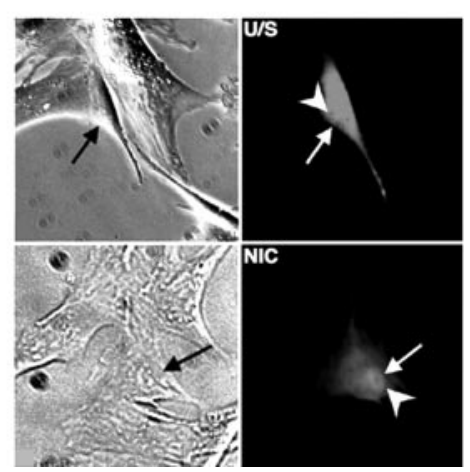

Fig. 5. Nicotine activates NFAT in human T cells. A and $\mathrm{B}$, activation of NFATc2 (A) and NFATc1 (B) was examined by electrophoretic mobility in primary competent $\mathrm{T}$ cells and Jurkat cells stimulated with antiCD3 for $6 \mathrm{~h}$ in the presence or absence of nicotine (NIC; $10 \mu \mathrm{M})$. Quantification of phosphorylated and dephosphorylated NFAT levels was done by densitometry, normalized to Zap-70 levels, and expressed as a fraction of the levels seen in competent cells (set to 1.00). The results from primary $\mathrm{T}$ cells show blots from one representative donor of four examined. C, Jurkat $\mathrm{T}$ cells were transfected with a construct encoding a GFPNFATc2 fusion protein and rested overnight. Cells were stimulated with soluble anti-CD3 (10 ng/ml) for $4 \mathrm{~h}$ in the absence or presence of nicotine (NIC; $10 \mu \mathrm{M}$ ) and FK506 (100 nM). C, DD-1 endothelial cells were similarly transfected and cultured in media containing serum without (U/T) or with $10 \mu \mathrm{M}$ nicotine (NIC) for $6 \mathrm{~h}$. Microscopic images were obtained under phase contrast (left) or fluorescent illumination (right) at $200 \times$ magnification from the same fields, where arrows indicate the same cells for paired images, and arrowheads point to nuclei. selective and nonselective nAChR antagonists. This suggests, alternatively, that low- and high-affinity $\mathrm{nAChR}$ act additively to activate (or suppress) the same signaling pathways or synergistically to engage distinct pathways that induce growth arrest at the $\mathrm{G}_{0} / \mathrm{G}_{1}$ boundary. This is a topic of ongoing investigation in our laboratories.

In addition to its effects on CDK4 expression, nicotineinduced NFAT activation could account for decreased cyclin D2 and increased p27Kip1 expression through transcriptional effects. However, recent data from our laboratory suggest that these effects on cyclin D2 and p27Kip1 expression also include alterations in ubiquitination and protein stability (A. Frazer-Abel, H. Meylemans, and J. Modiano, unpublished data). This is consistent with recent work showing that activation of calcineurin and NFAT modulates E3 ubiquitin ligase activity (Heissmeyer et al., 2004) and suggests that nicotine might also affect cell cycle progression through other previously unexplored pathways (e.g., protein stability) that are part of interactive receptor networks in non-neuronal cells. Such interactive networks have been characterized in B lymphocytes where there is cross talk between signals transmitted through $\beta$-adrenergic receptors and antigen receptors (Kohm et al., 2002). Thus, paradoxical effects of nic- otine on proliferation in different non-neuronal cell types might be due to the contextual cross talk between distinct $\mathrm{nAChR}$ and growth factor receptors (Leonard and Bertrand, 2001 ) or to the activation of different NFAT proteins (Kiani et al., 2000; Crabtree and Olson, 2002). In fact, such distinct nicotine effects may even occur in the same cell type at different stages of differentiation (Fosmire et al., 2004).

NFAT was initially characterized as a transcriptional activator of the IL-2 promoter, but it is now known that this requires cooperative binding with AP-1 proteins (Macian et al., 2001; Baksh et al., 2002; Crabtree and Olson, 2002). One consequence of NFATc2 activation without concurrent AP-1 activity is impairment of $\mathrm{T}$ cell competence (Baksh et al., 2002). However, NFATc2 is also important in polarization of $\mathrm{T}$ cells during the induction of humoral or cellular immune responses (Macian et al., 2001; Rengarajan et al., 2002), suggesting that timing and magnitude of NFAT activation can promote disparate effects in the same cells. Hence, activation of NFAT by nicotine in a temporally or quantitatively inappropriate context could lead to immunologic imbalance manifested by reduced cellular immunity.

Preliminary data from our laboratory suggest that $\mathrm{nAChR}$ are active participants in the maintenance of cellular quies- 

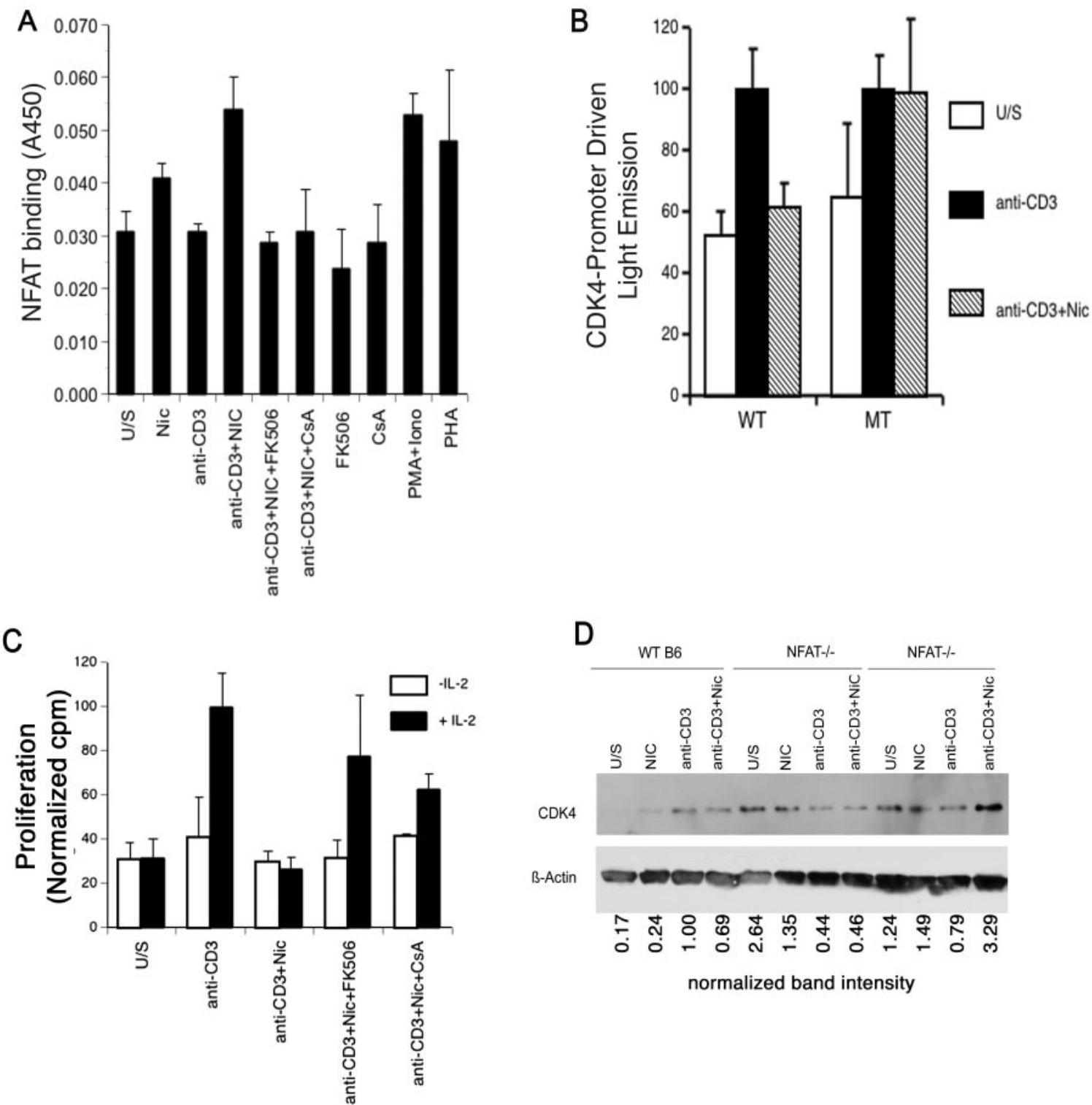

Fig. 6. Nicotine-activated NFATc2 binding of DNA is necessary to repress CDK4. A, activation of NFATc2 was examined by binding to oligonucleotides containing the NFAT core element in the untranslated region of CDK4 exon 1 (position +11). Nuclear extracts prepared from Jurkat cells treated as indicated for $4 \mathrm{~h}$ were incubated with the oligonucleotides, and binding was determined using a modified multiwell capture assay (see Materials and Methods). B, cells were transfected with wild-type CDK4 promoter construct (WT) or with a reporter that had a mutation in the core binding element for NFATc2 (TTTCC $\rightarrow$ AGAGT; MUT) and stimulated as in A. Data were normalized to the activity of Renilla luciferase and show mean change in stimulation ( \pm S.E.M.) where activity of competent cells was $100 \%$. C, T cells were isolated from a healthy human adult with no history of tobacco use and rendered competent by stimulation with soluble anti-CD3 in the presence or absence of nicotine, FK506 (100 nM), and CsA (1 $\mu$ M) as indicated. Proliferation was examined in at $48 \mathrm{~h}$ the presence or absence of IL-2 by ${ }^{3} \mathrm{H}$-thymidine incorporation. D, pooled T cells isolated from spleens of two wild-type mice (WT C57BL/6 mice), and T cells from spleens of two individual NFATc2-deficient mice (NFAT ${ }^{-\prime-}$ ) were rested overnight and left untreated or stimulated with anti-CD3 $(10 \mathrm{ng} / \mathrm{ml})$ for $4 \mathrm{~h}$ with or without nicotine $(10 \mu \mathrm{M})$ as indicated. Similar results were obtained in three animals for each genotype. Quantification of CDK4 protein in the immunoblot was done by densitometry, normalized to $\beta$-actin levels, and expressed as a fraction of the levels seen in cells stimulated using soluble anti-CD3 (set to 1.00).

cence, so it is not surprising that the sustained activation of these pathways by chronic exposure to tobacco might result in pathological phenotypes. Sopori's group showed that following chronic exposure to nicotine, rat $\mathrm{T}$ cells had elevated levels of "basal" signaling (Geng et al., 1996) but also impaired proliferative responses. Our present results show that $\mathrm{T}$ cells from habitual users of tobacco products are refractory to nicotine-dependent inhibition of CDK4 expression and proliferation. This suggests that, in the face of chronic exposure to tobacco products, there is a process of selection which favors cells that can circumvent the antiproliferative effects of nicotine and supports the notion that the activation of NFAT and T cell cycle arrest seen in response to nicotine are biologically significant. The consequences of inactivating cellular controls that inhibit CDK4 and the $\mathrm{G}_{0}$ to $\mathrm{G}_{1}$ transition are probably multifactorial. Acutely, inhibition of CDK4 activity could impair $\mathrm{T}$ cell responses and proliferation of other cell types involved in inflammation and tissue repair. Chronically, selection of cells that can circumvent the inhibitory effects of nicotine could be among the steps that contribute to neoplastic transformation. This observation offers a new, simple method that might be useful to monitor tobacco use, 


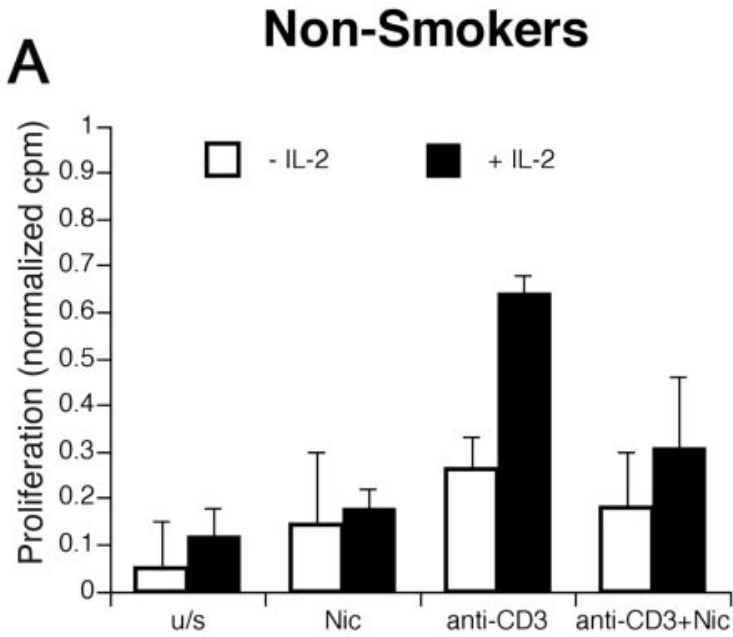

C

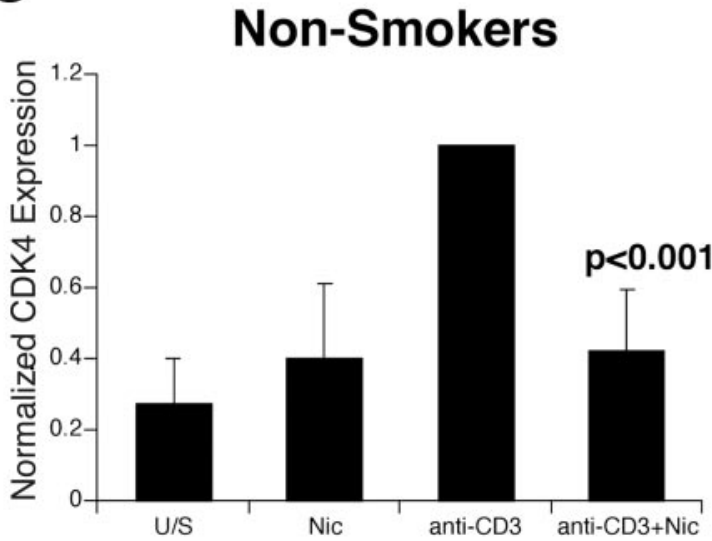

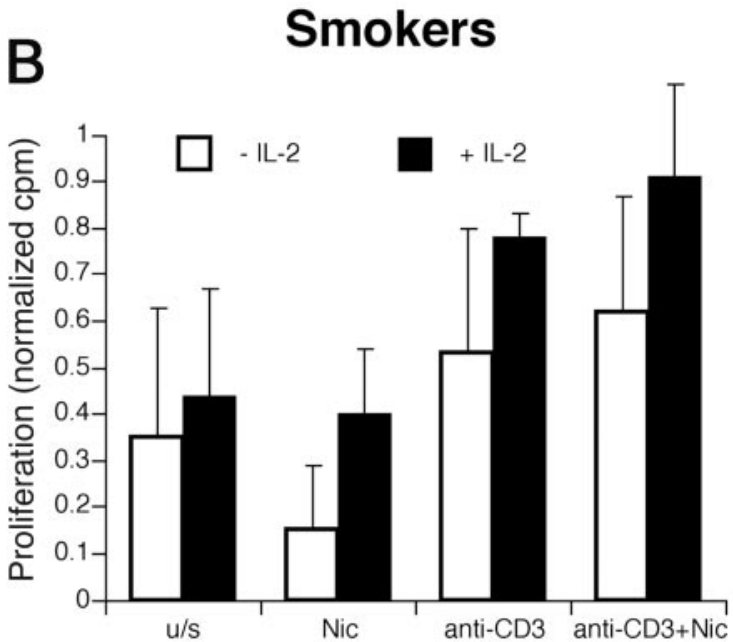

D

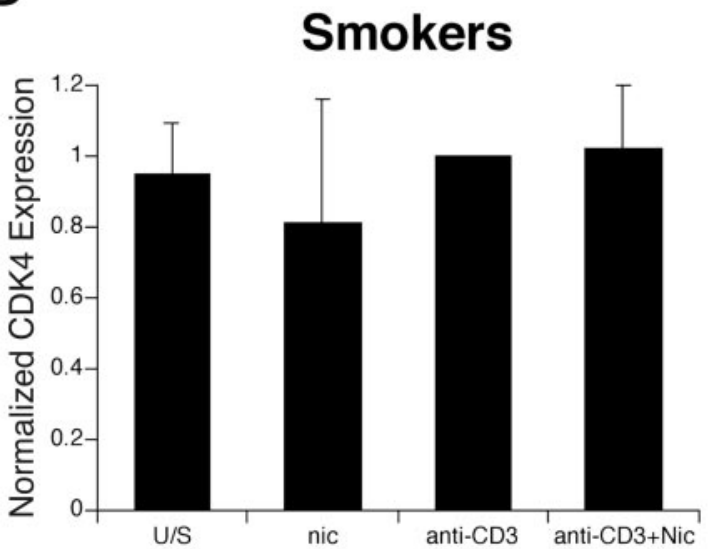

Fig. 7. Peripheral blood T cells from habitual users of tobacco products express CDK4 constitutively and are resistant to the antiproliferative effects of nicotine in vitro. PBTs were isolated from 14 healthy nonsmoking volunteers (A) and from 8 healthy tobacco users (B) and stimulated as in Fig. 1. Proliferation was measured by incorporation of ${ }^{3} \mathrm{H}$-thymidine, and the results were normalized to reflect the percentage of the maximal response seen for each donor. The data represent the normalized means \pm S.E.M. of proliferation for all donors. The effects of nicotine (inhibition of competence in the nonsmokers and enhanced proliferation in the tobacco users) were statistically significant $(P<0.01)$. PBTs from four nonsmokers $(\mathrm{C})$ and four smokers (D) were treated as in Fig. 3B, and CDK4 expression was evaluated by immunoblotting. Quantification of CDK4 protein levels was done by densitometry, normalized to the levels of $\beta$-actin, and expressed as a fraction of the expression levels seen in competent cells (set to 1.00). The data are presented as the means \pm S.E.M of normalized band intensities for CDK4 protein, where the levels in cells stimulated by anti-CD3 were set to 1.00. $P$ values and statistical significance were determined by Student's $t$ test for paired samples with two-tailed distribution.

exposure, and effects, for example, by following CDK4 expression in PBT from smokers in tobacco cessation programs.

The phenotype may not be restricted to up-regulation of CDK4 but rather may include a number of genes that participate in cell survival pathways, as suggested by the observation that lymphocytes from smokers showed constitutively increased expression of FasL (Suzuki et al., 1999). This could result in apoptosis of Fas-bearing neighboring cells, possibly interfering with antigen presentation by dendritic cells and antibody production by B cells, exacerbating immune-mediated lesions (Sopori, 2002). We do not believe these phenotypes arise from down-regulation or loss of function of nAChR. Nicotine binding stabilizes nAChR, delaying their down-regulation (Leonard and Bertrand, 2001), and nAChR gene expression is not diminished in PBT from tobacco users (Benhammou et al., 2000).

Recent work showed that nicotine can inhibit thymocyte proliferation in thymic organ cultures (Middlebrook et al., 2002). After 12 days in culture with nicotine, there were fewer surviving thymocytes, and these were mostly immature as defined by low levels of $\mathrm{T}$ cell receptor expression. Thymi from mice at 13 to 14 days of gestation appeared to be more sensitive to the nicotine effect than thymi from mice at 15 to 16 days. An explanation for the increased sensitivity of immature thymocytes, consistent with the results we present here, is that nicotine preferentially affects thymi where the proliferative fraction is higher. An eventual consequence of these effects could be that, in a hyperproliferative environment (such as the oral cavity or the lungs after a smoking insult), nicotine could interfere with the impetus for proliferation, leading to growth arrest and accelerated cell death. However, if the impaired proliferation were combined with the reported ability of nicotine exposure to inhibit apoptosis (Wright et al., 1993; Tohgi et al., 2000; Garrido et al., 2001; Sugano et al., 2001), one could envision a scenario where selection favors cells that render $G_{0} / G_{1}$ transition checkpoints and Fas pathways inconsequential for cell cycle progression and apoptosis, respectively. Hence, similar selective 
A
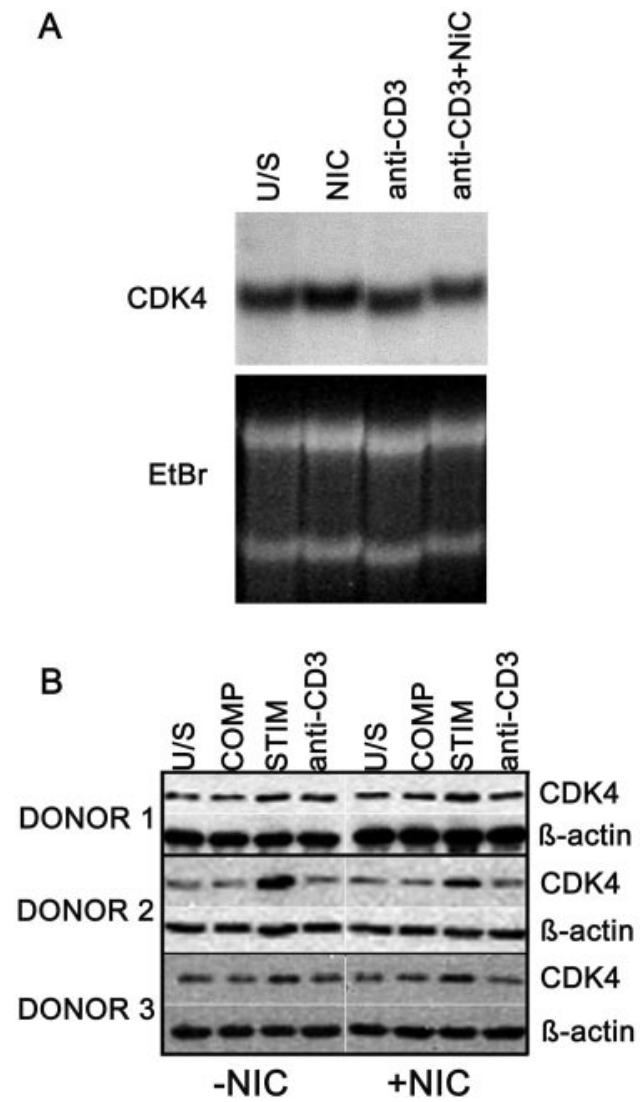

Fig. 8. Pre-existing CDK4 in $\mathrm{T}$ cells from habitual users of tobacco products is refractory to inhibition by nicotine. A, PBTs from a smoker were cultured as indicated with or without nicotine $(10 \mu \mathrm{M})$. CDK4 expression was evaluated by Northern blotting after $6 \mathrm{~h}$. B, PBTs from three smokers were rendered competent by suboptimal stimulation with PHA (COMP) or anti-CD3 or maximally stimulated (STIM) in the presence or absence of nicotine $(10 \mu \mathrm{M})$ as indicated. CDK4 expression was examined by immunoblotting 6 to $10 \mathrm{~h}$ after stimulation.

pressures to inactivate these pathways might contribute to commonly observed phenotypes of tobacco-associated head and neck tumors, which show lesions that inactivate the $\mathrm{Rb}$ pathway in up to $80 \%$ of cases (Forastiere et al., 2001) and may explain part of the enhanced risk of smokers to develop acute leukemias (Sandler et al., 1993).

In summary, we report that nicotine inhibits $\mathrm{T}$ cell cycle entry through activation of NFATc2 and repression of CDK4 expression and activity and that chronic exposure to tobacco products might favor selection of cells that are refractory to these effects. We postulate that cross talk between nAChR and growth factor receptor-activated pathways offers a novel mechanism by which nicotine can impinge on cell cycle progression. This provides insight into reasons that underlie disparate effects of nicotine on proliferation in distinct cell types and suggests that intervention strategies to prevent or control tobacco-related diseases might be developed to target proteins that regulate the $\mathrm{G}_{0} / \mathrm{G}_{1}$ transition of the cell cycle.

\section{Acknowledgments}

We thank Jesica McCue, Brian Freed, Pippa Marrack, Mohan Sopori, Tom Slaga, Sherri Leonard, Michelle Ritt, and Peter Nowell for helpful comments and suggestions; David Coffey and Cristan Jubala for expert technical help; the staff at the Blood Donor Center of The Children's Hospital (Denver, CO) for apheresis products; and
Karen Helm, Michael Ashton, and Tony Schountz for assistance with flow cytometry and phenotyping of PBTs.

\section{References}

Baksh S, Widlund HR, Frazer-Abel AA, Du J, Fosmire S, Fisher DE, DeCaprio JA Modiano JF, and Burakoff SJ (2002) NFATc2-mediated repression of cyclindependent kinase 4 expression. Mol Cell 10:1071-1081.

Benhammou K, Lee M, Strook M, Sullivan B, Logel J, Raschen K, Gotti C, and Leonard S (2000) [(3)H]Nicotine binding in peripheral blood cells of smokers is correlated with the number of cigarettes smoked per day. Neuropharmacology 39:2818-2829.

Carty CS, Huribal M, Marsan BU, Ricotta JJ, and Dryjski M (1997) Nicotine and its metabolite cotinine are mitogenic for human vascular smooth muscle cells. $J$ Vasc Surg 25:682-688.

Crabtree GR and Olson EN (2002) NFAT signaling: choreographing the social lives of cells. Cell 109 (Suppl):S67-S79.

Cucina A, Sapienza P, Corvino V, Borrelli V, Mariani V, Randone B, Santoro D'Angelo L, and Cavallaro A (2000) Nicotine-induced smooth muscle cell proliferation is mediated through bFGF and TGF-beta 1. Surgery 127:316-322.

Forastiere A, Koch W, Trotti A, and Sidransky D (2001) Head and neck cancer. N Engl J Med 345:1890-1900.

Fosmire SP, Dickerson EB, Bianco SR, Scott A, Pettengill M, Meylemans H, Padilla ML, Frazer-Abel AA, Akhtar N, Getzy DM, et al. (2004) Canine malignant heman giosarcoma as a model of primitive angiogenic endothelium. Lab Investig 84:562572

Garrido R, Mattson MP, Hennig B, and Toborek M (2001) Nicotine protects against arachidonic-acid-induced caspase activation, cytochrome c release and apoptosis of cultured spinal cord neurons. J Neurochem 76:1395-1403.

Geng Y, Savage SM, Johnson LJ, Seagrave J, and Sopori ML (1995) Effects of nicotine on the immune response: I. Chronic exposure to nicotine impairs antigen receptor-mediated signal transduction in lymphocytes. Toxicol Applied Pharmacol 135:268-278.

Geng Y, Savage SM, Razanai-Boroujerdi S, and Sopori ML (1996) Effects of nicotine on the immune response: II. Chronic nicotine treatment induces T cell anergy. $J$ Immunol 156:2384-2390.

Giannopoulou C, Roehrich N, and Mombelli A (2001) Effect of nicotine-treated epithelial cells on the proliferation and collagen production of gingival fibroblasts. $J$ Clin Periodontol 28:769-775.

Heissmeyer V, Macian F, Im SH, Varma R, Feske S, Venuprasad K, Gu H, Liu YC Dustin ML, and Rao A (2004) Calcineurin imposes T cell unresponsiveness through targeted proteolysis of signaling proteins. Nat Immunol 5:255-265.

Kalra R, Singh SP, Savage SM, Finch GL, and Sopori ML (2000) Effects of cigarette smoke on immune response: chronic exposure to cigarette smoke impairs antigenmediated signaling in T cells and depletes IP3-sensitive $\mathrm{Ca}^{(2+)}$ stores. J Pharmacol Exp Ther 293:166-171.

Kiani A, Rao A, and Aramburu J (2000) Manipulating immune responses with immunosuppressive agents that target NFAT. Immunity 12:359-372.

Kohm AP, Mozaffarian A, and Sanders VM (2002) B cell receptor- and beta 2-adren ergic receptor-induced regulation of B7-2 (CD86) expression in B cells. J Immunol 168:6314-6322.

Kuo Y, Lucero L, Michaels J, DeLuca D, and Lukas RJ (2002) Differential expression of nicotinic acetylcholine receptor subunits in fetal and neonatal mouse thymus. $J$ Neuroimmunol 130:140-154

Leonard S and Bertrand D (2001) Neuronal nicotinic receptors: from structure to function. Nicotine Tob Res 3:203-223.

Macian F, Garcia-Cozar F, Im SH, Horton HF, Byrne MC, and Rao A (2002) Transcriptional mechanisms underlying lymphocyte tolerance. Cell 109:719-731.

Macian F, Lopez-Rodriguez C, and Rao A (2001) Partners in transcription: NFAT and AP-1. Oncogene 20:2476-2489.

Middlebrook AJ, Martina C, Chang Y, Lukas RJ, and DeLuca D (2002) Effects of nicotine exposure on $\mathrm{T}$ cell development in fetal thymus organ culture: arrest of $\mathrm{T}$ cell maturation. J Immunol 169:2915-2924.

Modiano JF, Kelepouris E, Kern JA, and Nowell PC (1988) Requirement for extracellular calcium or magnesium in mitogen-induced activation of human peripheral blood lymphocytes. J Cell Physiol 135:451-458.

Modiano JF, Mayor J, Ball C, Chitko-McKown CG, Sakata N, Domenico-Hahn J, Lucas JJ, and Gelfand EW (1999) Quantitative and qualitative signals determin T-cell cycle entry and progression. Cell Immunol 197:19-29.

Modiano JF, Mayor J, Ball C, Fuentes MK, and Linthicum DS (2000) Cdk4 expression and activity are required for cytokine responsiveness in T cells. J Immunol 165:6693-6702.

Nel AE and Slaughter N (2002) T-cell activation through the antigen receptor. Part 2: role of signaling cascades in T-cell differentiation, anergy, immune senescence and development of immunotherapy. J Allergy Clin Immunol 109:901-915.

Renard P, Ernest I, Houbion A, Art M, Le Calvez H, Raes M, and Remacle J (2001) Development of a sensitive multi-well colorimetric assay for active NFkappaB Nucleic Acids Res 29:E21.

Rengarajan J, Tang B, and Glimcher LH (2002) NFATc2 and NFATc3 regulate TH2 differentiation and modulate TCR-responsiveness of naive TH cells. Nat Immunol 3:48-54.

Sandler DP, Shore DL, Anderson JR, Davey FR, Arthur D, Mayer RJ, Silver RT, Weiss RB, Moore JO, and Schiffer CA (1993) Cigarette smoking and risk of acute leukemia: associations with morphology and cytogenetic abnormalities in bone marrow. J Natl Cancer Inst 85:1994-2003.

Sherr CJ and Roberts JM (1995) Inhibitors of mammalian cyclin-dependent kinases. Genes Devel 9:1149-1163.

Singh SP, Kalra R, Puttfarcken P, Kozak A, Tesfaigzi J, and Sopori ML (2000) Acute and chronic nicotine exposures modulate the immune system through different pathways. Toxicol Appl Pharmacol 164:65-72. 
Sopori M (2002) Effects of cigarette smoke on the immune system. Nat Rev Immunol 2:372-377.

Sopori ML, Kozak W, Savage SM, Geng Y, and Kluger MJ (1998) Nicotine-induced modulation of T cell function: implications for inflammation and infection. Adv Exp Med Biol 437:279-289.

Sugano N, Minegishi T, Kawamoto K, and Ito K (2001) Nicotine inhibits UV-induced activation of the apoptotic pathway. Toxicol Lett 125:61-65.

Suzuki N, Wakisaka S, Takeba Y, Mihara S, and Sakane T (1999) Effects of cigarette smoking on Fas/Fas ligand expression of human lymphocytes. Cell Immunol 192: $48-53$

Theilig C, Bernd A, Ramirez-Bosca A, Gormar FF, Bereiter-Hahn J, KellerStanislawski B, Sewell AC, Rietbrock N, and Holzmann H (1994) Reactions of human keratinocytes in vitro after application of nicotine. Skin Pharmacol 7:307315.

Tohgi H, Utsugisawa K, and Nagane Y (2000) Protective effect of nicotine through nicotinic acetylcholine receptor alpha 7 on hypoxia-induced membrane disintegration and DNA fragmentation of cultured PC12 cells. Neurosci Lett 285:91-94
Toyabe S, Iiai T, Fukuda M, Kawamura T, Suzuki S, Uchiyama M, and Abo T (1997) Identification of nicotinic acetylcholine receptors on lymphocytes in the periphery as well as thymus in mice. Immunology 92:201-205.

Villablanca AC (1998) Nicotine stimulates DNA synthesis and proliferation in vascular endothelial cells in vitro. J Appl Physiol 84:2089-2098.

Wright SC, Zhong J, Zheng H, and Larrick JW (1993) Nicotine inhibition of apoptosis suggests a role in tumor promotion. FASEB $J$ 7:1045-1051.

Xanthoudakis S, Viola JP, Shaw KT, Luo C, Wallace JD, Bozza PT, Luk DC, Curran $\mathrm{T}$, and Rao A (1996) An enhanced immune response in mice lacking the transcription factor NFAT1. Science (Wash DC) 272:892-895.

Zhang S and Petro TM (1996) The effect of nicotine on murine CD4 T cell responses. Int $J$ Immunopharmacol 18:467-478.

Address correspondence to: Dr. Jaime F. Modiano, AMC Cancer Center/ UCHSC, 2-Diamond Building, 1600 Pierce Street, Denver, CO 80214. E-mail: modianoj@amc.org 